Pengaruh Pemberian Tugas Awal Pada Pembelajaran Ekspositori terhadap Hasil Belajar Siswa Kelas XI IPA SMAN II Makassar

\title{
Pengaruh Pemberian Tugas Awal dalam Pembelajaran Ekspositori terhadap Hasil Belajar Siswa SMAN 11 Makassar (Materi Pokok Kesetimbangan Kimia)
}

\author{
The Influence of Pre-Task in Expository Learning to Students' Learning \\ Achievement of Clas XI IPA in SMA Negeri 11 Makassar \\ (Balance Chemical Reactions Subject Matter) \\ ${ }^{1)}$ Nurfadzillah, ${ }^{2)}$ Muhammad Danial, ${ }^{3)}$ Army Auliah \\ ${ }^{123)}$ Jurusan Kimia Fakultas Matematika dan Ilmu Pengetahuan Alam \\ Universitas Negeri Makassar, Jl. Dg Tata Raya Makassar, Makassar 9022
}

\begin{abstract}
ABSTRAK
Jenis penelitian ini adalah penelitian eksperimen semu dengan tujuan untuk mengetahui pengaruh pemberian tugas awal dalam pembelajaran ekspositori terhadap hasil belajar siswa. Populasinya adalah kelas XI IPA SMA Negeri 11 Makassar Tahun ajaran 2015/2016 yang terdiri dari 7 Kelas. Pengambilan sampel melalui teknik random sehingga diperoleh kelas XI IPA 1 sebagai kelas eksperimen dan XI IPA ${ }_{2}$ sebagai kelas kontrol dengan jumlah masing-masing siswa yang dijadikan sampel adalah 32 orang. Variabel bebasnya adalah pemberian tugas awal dalam pembelajaran ekspositori pada kelas eksperimen dan pembelajaran ekspositori pada kelas kontrol, sedangkan variabel terikatnya adalah hasil belajar siswa. Pengumpulan data dilakukan dengan menggunakan tes hasil belajar siswa yang dianalisis dengan Statistik Deskriptif dan Statistik Inferensial dengan bantuan SPSS versi 20. Hasil analisis Deskriptif menunjukkan perolehan nilai rata-rata post-test untuk kelas eksperimen sebesar 67,63 sedangkan kelas kontrol 57,32. Berdasarkan hasil analisis statistik inferensial diperoleh nilai signifikansi sebesar $\mathrm{p}=0,046<\alpha=$ 0,05 yang berarti bahwa $\mathrm{H}_{0}$ ditolak dan $\mathrm{H}_{1}$ diterima. Hal ini dapat disimpulkan bahwa Pemberian Tugas Awal dalam Pembelajaran Ekspositori berpengaruh positif terhadap hasil belajar siswa kelas XI IPA SMA Negeri 11 Makassar pada materi kesetimbangan kimia.
\end{abstract}

Kata Kunci: Tugas Awal, Ekspositori, Hasil Belajar 


\begin{abstract}
This research was an experimental research which aimed to discover the influence of pre-task in expository learning to students' learning achievement of Kelas XI IPA in SMA Negeri 11 Makassar, Academic Year of 2015/2016. There are 6 classes of Kelas XI IPA in SMA Negeri 11 Makassar. This research used simple random sampling, where Kelas XI IPA 1 as the experimental class and Kelas XI IPA 2 as the control class. Each class contains of 32 students. The independent variable is pre-task in expository learning for the experimental class, and expository learning for the control class. The dependent variable is students' leraning achievement. The data collection was obtained by the descriptive statistical and inferential statistical analysis of students' test result using SPSS analysis version 20. The result of descriptive statistical analysis showed the mean score of post-test in experimental class was 67,63 and 57,32 in control class. For the result of inferential statistical analysis showed significance value of $\mathrm{p}=0,046<\alpha=0,05$ which means $\mathrm{H}_{0}$ (null hypothesis) was rejected and $\mathrm{H}_{1}$ (alternative hypothesis) was accepted. It is concluded that pre-task in learning expository has positive influence to students' learning achievement of Kelas XI IPA in SMA Negeri 11 Makassar.
\end{abstract}

Key word: Pre-Task, Expository Learning, Learning Achievement

\section{PENDAHULUAN}

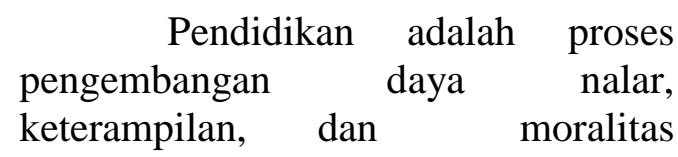

kehidupan pada potensi yang dimiliki oleh setiap manusia. Pendidikan menjadi satu alat yang digunakan untuk mengembangkan potensi hidup manusia, baik dari keterampilan dan moralitas. Oleh karena itu pendidikan merupakan satu hal penting yang menjadi kebutuhan manusia, yang mempunyai pengaruh yang sangat besar terhadap pembentukan karakter manusia, sehingga dibutuhkan suatu pendidikan yang berkualitas dan bermutu dalam mendidik anak-anak bangsa (Trianto, 2009).

Dunia pendidikan hari ini sangat sering menghadapi berbagai macam masalah salah satunya adalah lemahnya proses pembelajaran. Dalam proses pembelajaran, anak kurang didorong untuk mengembangkan kemampuan berpikir. Proses pembelajaran di dalam kelas diarahkan kepada kemampuan anak untuk menghafal informasi, otak anak dipaksa untuk mengingat dan menimbun berbagai informasi tanpa dituntut untuk memahami informasi yang diingatnya.

Kenyataan ini berlaku pada salah satu mata pelajaran di sekolah pada umumnya yaitu kimia, berdasarkan hasil observasi di SMAN 11 Makassar, diperoleh data nilai ulangan harian siswa yang sebagian besar tidak mencapai nilai KKM yang telah ditentukan, hal ini bisa disebabkan oleh lemahnya proses pembelajaran sehingga siswa merasa tidak tertarik dan tidak mau mempelajarinya, Oleh karena itu 
$\begin{array}{lrr}\text { dibutuhkan } & \text { sebuah } & \text { proses } \\ \text { pembelajaran } & \text { yang } & \text { dapat }\end{array}$ menumbuhkan sikap rasa ingin tahu siswa.

Salah satu strategi pembelajaran yang dapat digunakan seorang guru adalah strategi pemberian tugas awal dengan pembelajaran ekspositori. Strategi pembelajaran ekspositori adalah strategi pembelajaran yang menekankan kepada proses penyampaiaan materi secara verbal dari seorang guru kepada sekelompok siswa dengan maksud agar siswa dapat menguasai materi pelajaran secara optimal. Strategi ekspositori lebih dikenal dengan istilah strategi pembelajaran langsung (direct instruction). Sehingga dalam hal ini guru aktif menjelaskan dengan memperkecil adanya miss konsepsi di kalangan siswa. Untuk menciptakan terjadinya interaksi, menarik perhatian siswa dan melatih keterampilan siswa strategi ini biasanya dikombinasikan dengan strategi Tanya jawab dan pemberian tugas. Strategi pemberian tugas dapat mengaktifkan peran siswa dalam proses pembelajaran.

Pemberian Tugas awal dapat membuat proses belajar menjadi menyenangkan, efektif, dan efisien. Tugas awal dapat pula memberikan kesempatan kepada siswa untuk menerima informasi baru, mengaplikasikan, menganalisis bahkan mengevaluasi informasi tersebut, sehingga tidak hanya guru, siswa terlibat aktif dalam proses pembelajaran pula, dan tentu tidak akan terjadi kesalahan pemahaman konsep karena dalam pembelajaran ekspositori guru menjelaskan secara langsung materi dan mengevaluasi tugas siswa secara langsung, dan memberikan penghargaan.

Tugas awal yang dikerjakan siswa akan menjadi bekal awal siswa dalam belajar. Persiapan yang dimiliki siswa diperkirakan dapat membuat proses belajar mengajar lebih interaktif dimana siswa tidak lagi takut salah dalam menyampaikan pendapat karena mereka telah memiliki sejumlah pengetahuan. Dengan pengetahuan yang dimiliki siswa melalui tugas awal ini, proses pembelajaran diharapkan akan menjadi lebih bermakna bagi siswa dan diharapkan dapat menjawab pertanyaan-pertanyaan yang disampaikan guru saat Proses pembelajaran berlangsung sehingga Proses pembelajaran yang terjadi lebih interaktif dan diharapkan pencapaian hasil belajar siswa menjadi lebih baik.

Penelitian ini bertujuan untuk mengetahui pengaruh pemberian tugas awal dalam pembelajaran ekspositori terhadap hasil belajar siswa kelas XI IPA SMA Negeri 11 Makassar pada Materi Pokok Kesetimbangan Kimia.

\section{METODE PENELITIAN}

Penelitian ini merupakan penelitian eksperimen semu dengan desain posttest kontrol group design pada Tabel 1.

Tabel 1. Pola Desain Penelitian

\begin{tabular}{lcl}
\hline \multicolumn{1}{c}{ Kelas } & $\begin{array}{c}\text { Perla- } \\
\text { kuan }\end{array}$ & $\begin{array}{c}\text { Post } \\
\text {-test }\end{array}$ \\
\hline Eksperimen & $\mathrm{T}_{1}$ & $\mathrm{O}_{1}$ \\
Kontrol & $\mathrm{T}_{2}$ & $\mathrm{O}_{2}$ \\
\hline
\end{tabular}

(Sugiyono: 2012). 
Penelitian ini dilaksanakan di SMAN 11 Makassar pada semester ganjil tahun ajaran 2015/2016. Populasi dalam penelitian ini adalah seluruh siswa kelas XI IPA SMAN 11 yang terdiri dari tujuh kelas. Sampel dipilih dengan teknik random sederhana (simple random sampling). Dari ketujuh kelas tersebut diperoleh 2 kelas, yaitu kelas XI IPA 1 sebagai kelas eksperimen dengan jumlah siswa 32 orang dan kelas XI IPA II sebagai kelas kontrol dengan jumlah siswa 32 orang.

Instrumen yang diberikan berupa soal Essay yang terdiri dari 5 nomor. Skor yang diperoleh siswa diubah ke nilai dengan menggunakan rumus:

$$
\text { Nilai }=\frac{\text { Skor yang diperoleh siswa }}{\text { Skor maksimum }} \times 100
$$$$
\text { Untuk menguji pengaruh }
$$
pemberian tugas awal dalam pembelajaran ekspositori dilakukan dengan analisis statistik deskriptif dan inferensial dengan menggunakan program SPSS (Statistical Product and Service Solution)

Statistik inferensial merupakan analisis statistik yang digunakan untuk menganalisis data sampel dan hasilnya digunakan untuk populasi. Analisis ini digunakan untuk menguji hipotesis dengan menggunakan program SPSS (Statistical Product and Service Solution) versi 20. Sebelum uji hipotesis terlebih dahulu dilakukan uji prasyarat berupa uji normalitas dan uji homogenitas data.

\section{A. Uji Prasyarat 1. Uji Normalitas}

Uji normalitas adalah pengujian terhadap normal tidaknya sebaran data yang akan dianalisis. Pengujian normalitas menggunakan taraf signifikansi 5\% atau 0,05. Data bersifat normal jika nilai signifikan lebih besar dari 5\% (nilai sig > 0.05). Pada taraf signifikan $\alpha=0,05$, jika signifikansi yang diperoleh $>\alpha$, maka sampel berasal dari populasi data yang berdistribusi normal. Sedangkan jika signifikansi yang diperoleh $<\alpha$, maka sampel berasal dari populasi data yang tidak berdistribusi normal (Santoso, 2014).

\section{Uji Homogenitas}

Pengujian homogenitas untuk mengetahui data yang diteliti berasal dari populasi yang homogen. Pengujian homogenitas dilakukan dengan bantuan program SPSS (Statistical Product and Service Solution) versi 20 menggunakan Levene Test. Data bersifat homogen jika nilai signifikan lebih besar dari $5 \%$ (nilai sig > 0.05). Pada taraf signifikan $\alpha=0.05$, jika signifikansi yang diperoleh $>\alpha$, maka data berasal dari populasi yang homogen. Jika signifikansi yang diperoleh $<\alpha$, maka data berasal dari populasi yang tidak homogen (Santoso, 2014).

\section{B. Uji Hipotesis}

Uji hipotesis digunakan untuk menguji hipotesis yang telah dirumuskan. Pengujian hipotesis dilakukan dengan bantuan program SPSS (Statistical Product and Service Solution) versi 20. Pengujian 
dilakukan melalui Independent Samples $t$ Test Analisis Independent sample T-test pada dasarnya digunakan untuk mengetahui ada atau tidaknya perbedaan rata-rata antara dua kelompok sampel yang tidak berhubungan. Jika ada perbedaan, ratarata manakah yang lebih tinggi, sehingga penggunaannya tidak terbatas kepada pengujian perbedaan dua buah rata-rata populasi, namun dapat juga untuk menguji perbedaan tiga buah rata-rata populasi atau lebih.

Digunakan uji perbedaan dua rata-rata (Independent Sample T Test) yaitu:

$H_{0}: \mu_{1} \leq \mu_{2}$

$H_{1}: \mu_{1}>\mu_{2}$

$\mu_{1}$ : rata-rata skor hasil belajar kimia siswa yang diberi perlakuan dengan pemberian tugas awal dalam pembelajaran ekspositori

$\mu_{2}$ : rata-rata skor hasil belajar kimia siswa yang diberi perlakuan tanpa pemberian tugas dalam pembelajaran ekspositori.

Kriteria pengujian hipotesisnya sebagai berikut: Menolak $\mathrm{H}_{0}$ apabila nilai nilai $\mathrm{P}_{\text {value }}<0,05$ Teknik analisis statistik yang dikemukakan diatas dilakukan dengan menggunakan pengolah data Statistical Package for Social Science (SPSS) versi 20,0 for windows. Digunakan Independent sample t test (Uji t sampel independen) dengan kriteria pengujian hipotesis $\mathrm{H}_{0}$ ditolak dan $\mathrm{H}_{1}$ diterima jika nilai $\mathrm{P}_{\text {value }}<0,05$ sedangkan hipotesis $\mathrm{H}_{0}$ diterima dan $\mathrm{H}_{1}$ ditolak jika nilai $\mathrm{P}_{\text {value }}>0,05$.

Keterangan:
$\mathrm{H}_{0}=$ Tidak ada pengaruh pemberian tugas awal dalam pembelajaran ekspositori terhadap hasil belajar siswa kelas XI IPA SMA Negeri 11 Makassar (studi pada materi pokok Kesetimbangan kimia).

$\mathrm{H}_{1}=$ Ada pengaruh pemberian tugas awal dalam pembelajaran ekspositori terhadap hasil belajar siswa kelas XI IPA SMA Negeri 11 Makassar (studi pada materi pokok Kesetimbangan kimia).

Adapun kriteria ketuntasan pada SMAN 11 Makassar dinyatakan pada Tabel 2.

Tabel 2. Kriteria Ketuntasan SMAN 11 Makassar

\begin{tabular}{|c|c|}
\hline $\begin{array}{c}\text { Tingkat } \\
\text { Penguasaan }\end{array}$ & Kategori \\
\hline$\geq 75$ & Tuntas \\
\hline$<75$ & Tidak Tuntas \\
\hline
\end{tabular}

HASIL DAN PEMBAHASAN

A. Hasil Penelitian

1. Analisis Deskriptif

Berdasarkan

hasil

pengolahan data dengan statistik deskriptif diperoleh nilai statistik deskriptif hasil belajar siswa (posttest) kelas eksperimen dan kelas kontrol dapat dilihat pada Tabel 2. 
Tabel 2. Deskripsi Hasil Belajar Siswa Kelas Kontrol dan Kelas Ekperimen

\begin{tabular}{clc}
\hline \multirow{2}{*}{ Statistik } & \multicolumn{2}{c}{ Nilai Statistik } \\
\cline { 2 - 3 } & Kontrol & Eksperimen \\
\cline { 2 - 3 } & Post-test & \multicolumn{1}{c}{ Post-test } \\
\hline $\begin{array}{c}\text { Jumlah } \\
\text { sampel }\end{array}$ & 32 & 32 \\
\hline $\begin{array}{c}\text { Nilai } \\
\text { terendah }\end{array}$ & 27.77 & 28.88 \\
\hline $\begin{array}{c}\text { Nilai } \\
\text { tertinggi }\end{array}$ & 100 & 100 \\
\hline $\begin{array}{c}\text { Nilai rata- } \\
\text { rata (mean) }\end{array}$ & 57.32 & 67.63 \\
\hline $\begin{array}{c}\text { Median } \\
\text { (Me) }\end{array}$ & 69.22 & 79.78 \\
\hline $\begin{array}{c}\text { Modus } \\
\text { (Mo) }\end{array}$ & 60.21 & 76.16 \\
\hline $\begin{array}{c}\text { Standar } \\
\text { Deviasi }\end{array}$ & 19.92 & 20.66 \\
\hline
\end{tabular}

Tabel 2 menunjukkan bahwa ada perbedaan secara jelas yang terlihat pada nilai tes hasil belajar siswa untuk kelas eksperimen dan kelas kontrol. Adapun persentase dan pengkategorian ketuntasan hasil belajar siswa pada dua kelas dapa dilihat pada Gambar 1.

Gambar 1 menunjukkan bahwa ketuntasan yang diperoleh kelas ekperimen lebih tinggi dibandingkan kelas kotrol. Hal tersebut menunjukkan bahwa pemberian tugas awal pada pembelajaran ekspositori yang digunakan pada kelas eksperimen memberikan hasil belajar yang lebih inggi dibandingkan dengan kelas kontrol yang hanya menggunakan pembelajaran ekspositori tanpa pemberian tugas awal.

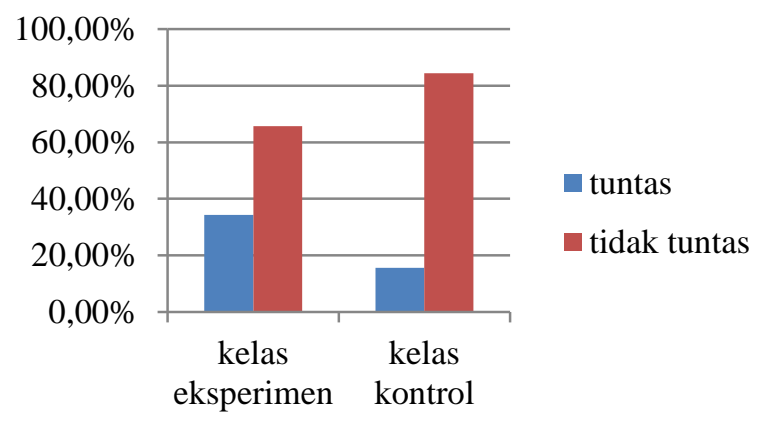

Gambar 1. Diagram Batang Persentase Ketuntasan Kelas Eksperimen dan Kelas Kontrol

2. Analisis Statistik Inferensial

a. Pengujian prasyarat analisis

1) Uji Normalitas

Berdasarkan hasil analisis data dengan menggunakan uji onesample Shapiror-wilk diperoleh hasil data post-test terdistribusi normal dengan nilai signifikansi $\mathrm{p}=0,171>\alpha$ $=0,05$. Kriteria pengujian data berdistribusi normal jika nilai signifikansi lebih besar daripada 0,05 .

\section{2) Uji Homogenitas}

Berdasarkan hasil pengolahan data dengan menggunakan Levene's Test untuk data post-test diperoleh nilai signifikansi $\mathrm{p}=0,816>\alpha=0,05$, sehingga sampel bersifat homogen. 
Berdasarkan kriteria pengujian data bersifat homogen jika nilai signifikansi lebih besar dari alfa $(\mathrm{p}>\alpha$ $=0,05)$.

\section{b. Pengujian Hipotesis}

Berdasarkan pengujian prasyarat analisis, diperoleh nilai posttest berdistribusi normal dan varians data sampel dinyatakan homogen. Selanjutnya pengujian hipotesis

Berdasarkan hasil analisis tersebut, maka hipotesis $\mathrm{H}_{0}$ ditolak dan $\mathrm{H}_{1}$ diterima. Hal ini berarti Ada pengaruh pemberian tugas awal dalam pembelajaran ekspositori terhadap hasil belajar siswa kelas XI IPA SMA Negeri 11 Makassar (studi pada materi pokok Kesetimbangan Kimia).

\section{B. Pembahasan}

Berdasarkan hasil analisis deskriptif dengan menggunakan program SPSS ini menunjukkan bahwa ada perbedaan hasil belajar siswa antara kelas ekperimen dengan perlakuan pemberian tugas awal dalam pembelajaran ekspositori dengan kelas kontrol yang tidak diberi pemberian tugas awal dalam pembelajaran ekspositori, namun dalam hal ini belum dapat disimpulkan bahwa pemberian tugas awal dalam pembelajaran ekspositori memiliki pengaruh positif terhadap hasil belajar siswa, sehingga perlu dilakukan uji analisis statistik inferensial dengan menggunakan program SPSS.

Persentase ketuntasan hasil belajar siswa pada kelas kontrol adalah $15,63 \%$ sedangkan pada kelas eksperimen 34,47\%, hal ini menunjukkan adanya peningkatan pada hasil belajar siswa pada kelas eksperimen yang diberi perlakuan dengan pemberian tugas awal pada pembelajaran ekspositori baik hasil belajar kognitif, psikomotorik dan afektif. Secara eksplisit ketiga ranah ini tidak dapat dipisahkan satu sama lain. Sehingga berdasarkan Persentase Ketuntasan siswa pada kelas eksperimen menunjukkan hasil belajar psikomotorik juga meningkat Karena ranah psikomotor adalah ranah yang sangat berhubungan dengan aktivitas fisik seperti menulis, semakin tepat siswa menulis jawaban dari tes kognitif bentuk essay maka semakin mungkin siswa untuk mencapai ketuntasan, demikian pula dengan hasil belajar afektif (sikap) ini sangat menentukan keberhasilan siswa mencapai ketuntasan. Sikap positif siswa terhadap proses pembelajaran dapat meningkatkan pencapaiaan hasil belajar. Sehingga ketika persentase ketuntasan siswa pada kelas eksperimen meningkat maka hal ini menunjukkan sikap positif siswa pada kelas eksperimen juga meningkat.

Adapun persentase ketidaktuntasan pada kelas kontrol adalah $84,37 \%$ sedangkan pada kelas eksperimen 65,63\%, hal ini menandakan bahwa belum mencapai minimal ketuntasan $80 \%$. Ketidaktuntasan dapat dipengaruhi oleh dua aspek yakni aspek dari guru dan aspek dari siswa. Dari aspek guru yang perlu ditingkatkan adalah kegiatan apersepsi, artinya guru masih perlu memperkaya pengetahuan baik materi yang telah diajarkan maupun materi yang belum diajarkan. Sedangkan pada aspek siswa masih 
ada beberapa siswa yang tidak disiplin mengikuti kegiatan pembelajaran, tidak memperhatikan tujuan, motivasi serta penjelasan guru. Meskipun persentase ketidaktuntasan setiap kelas masih tinggi tapi kelas eksperimen yang diberi perlakuan pemberian tugas awal pada pembelajaran ekspositori memiliki persentase ketidaktuntasan yang lebih rendah.

Pembahasan hasil analisis statistik inferensial yang dimaksudkan adalah pembahasan terhadap hasil pengujian hipotesis yang telah dikemukakan sebelumnya. Hasil uji statistik $\mathrm{H}_{0:} \quad \mu_{1} \leq \mu_{2} \quad$ dengan menggunakan uji-t telah diperoleh nilai $\operatorname{sig}(2$-tailed $)=0,046<0,05=$ $\alpha$, menunjukkan $\mathrm{H}_{0}$ ditolak. Secara inferensial ini berarti selisih skor hasil belajar siswa yang diberi perlakuan dengan pemberian tugas awal dalam pembelajaran ekspositori lebih besar dari selisih skor hasil belajar siswa tanpa pemberian tugas awal dalam pembelajaran ekspositori.

Dengan demikian dapat disimpulkan bahwa pemberian tugas awal dalam pembelajaran ekspositori dapat meningkatkan hasil belajar siswa dibanding dengan hanya menggunakan metode pembelajaran ekspositori, pemberian tugas awal memberikan kesempatan kepada siswa untuk aktif dan merangsang pengetahuan awal mereka terhadap materi yang akan dibahas sebelum dijelaskan oleh guru. Sehingga pengetahuan-pengetahuan ini akan melatih cara berpikir siswa, dan merangsang siswa untuk bertanya jika ada yang belum jelas. Sehingga pemberian tugas awal dalam pembelajaran ekspositori dapat meningkatkan hasil belajar siswa. Pelaksanaan pemberian tugas awal ini juga mendorong siswa untuk belajar dan mencari tahu jawaban dari tugas yang diberikan secara mandiri sehingga diharapkan hasil belajar dapat meningkat, agar proses pembelajaran tidak berpusat pada guru. Hal ini juga sesuai dengan (Masnun, 2009) dalam penelitiannya yang berjudul Efektivitas Pemberian Tugas Dalam meningkatkan Hasil Belajar Siswa Kelas XI IPS Pada Mata Pelajaran Matematika Di SMA Ma'arif Bulakamba Kabupaten Brebes menyimpulkan bahwa pemberian tugas efektif dalam meningkatkan hasil belajar matematika.

Berbeda halnya dengan kelas tanpa pemberian tugas awal, hanya dengan menggunakan metode pembelajaran ekspositori proses pembelajaran ini lebih berpusat pada guru sehingga siswa tidak bekerja secara mandiri, dan tidak terlibat secara aktif bahkan terkesan pasif. Dalam pembelajaran dengan menggunakan metode tugas dan resitasi lebih baik karena mampu mengaktifkan siswa dalam proses belajar mengajar, dan memberikan kesempatan kepada siswa untuk mengemukakan pendapatnya masingmasing. 


\section{KESIMPULAN DAN SARAN}

\section{A. KESIMPULAN}

Berdasarkan hasil analisis data dan pembahasan, maka dapat ditarik kesimpulan bahwa pemberian tugas awal dalam dalam pembelajaran ekspositori berpengaruh positif terhadap hasil belajar siswa kelas XI IPA SMA Negeri 11 Makassar pada Materi Pokok Kesetimbangan Kimia.

\section{B. SARAN}

Berdasarkan hasil penelitian
ini disarankan agar dalam
melaksanakan penelitian yang serupa
peneliti mengelolah waktu secara
disiplin agar rencana pelaksanaan
pembelajaran dapat terlaksana dengan
baik.

\section{DAFTAR PUSTAKA}

Masnun, Moh.dkk. 2009. Efektivitas Pemberian Tugas Dalam Meningkatkan Hasil Belajar Siswa Kelas XI IPS Pada Mata Pelajaran Matematika di SMA Ma'arif Bulakamba Kabupaten Brebes. EduMa.Vol.1, No.1.

Santoso, Singgih. 2014. Panduan Lengkap SPSS Versi 20 Edisi Revisi. Jakarta: PT. Elex Media Komputindo.

Sugiyono, 2012 . Metode Penelitian Kuantitatif Kualitatif dan $R$ \& D. Bandung: Alfabeta

Trianto, 2009. Mendesain Model Pembelajaran Inovatif Progresif. Jakarta : Kencana 